\title{
ACUTE DERMAL TOXICITY STUDY OF ARECA CATECHU LINN. EXTRACT IN SPRAGUE-DAWLEY RATS
}

\author{
LIZA MEUTIA SARI ${ }^{1 *}$, FRANS D SUYATNA ${ }^{2}$, GUS PERMANA SUBITA ${ }^{3}$, ELZA IBRAHIM AUERKARI ${ }^{4}$
}

${ }^{1}$ Department of Oral Medicine, Faculty of Dentistry, Indonesia University, Jakarta, Indonesia. ${ }^{2}$ Department of Pharmacology and Therapeutic, Faculty of Medicine, Indonesia University, Jakarta, Indonesia. ${ }^{3}$ Department of Oral Medicine, Faculty of Dentistry, Indonesia University, Jakarta, Indonesia. ${ }^{4}$ Department of Oral Biology, Faculty of Dentistry, Indonesia University, Jakarta, Indonesia. Email: zazalukman@yahoo.com

Received: 03 August 2016, Revised and Accepted: 05 September 2016

\section{ABSTRACT}

Objective: Areca catechu Linn. or biji pinang is one of the most widely used psychoactive substance with several hundred million users worldwide, predominantly in Southern Asia. However, details of the dermal toxicity of $A$. catechu L. are still undiscovered. The objective of this study is to investigate the in vivo acute dermal toxicity of aqueous extract of $A$. catechu L. at dose 15,000 mg/kg body weight in Sprague-Dawley rats.

Methods: The acute dermal toxicity of $A$. catechu L. nut extract was investigated in rats, as per OECD Guidelines 402 for acute toxicity protocols. The body weight, possibility of death, general signs, and behavior activity parameters were measured for 14 days to ascertain the median lethal dose (LD50) of the extract. At the end of the study, all the animals in all the treated group were sacrificed.

Results: The LD50 was found to be $>15,000 \mathrm{mg} / \mathrm{kg}$ body weight. There was significant weight increase ( $<<0.05$ ) in treated group when compared to control group. No mortality was observed during whole 14 days study period. A single dose of $15,000 \mathrm{mg} / \mathrm{kg}$ of body weight did not produce treatment-related signs of toxicity in any of animal tested.

Conclusion: A single dermal dose to A. catechu L. aqueous extract had no toxic effects on mortality, clinical signs, body weight changes, and gross findings in female rats at a dose of $15,000 \mathrm{mg} / \mathrm{kg}$ of body weight. Subsequently, the concentrate can be employed for pharmaceuticals nutrient plants.

Keywords: A. catechu L., Acute dermal toxicity, LD50.

(C) 2016 The Authors. Published by Innovare Academic Sciences Pvt Ltd. This is an open access article under the CC BY license (http://creativecommons. org/licenses/by/4. 0/) DOI: http://dx.doi.org/10.22159/ajpcr.2016.v9s3.14462

\section{INTRODUCTION}

Areca catechu Linn. (family Palmaceae), commonly known as an important economical seed crop, is widely cultivated in tropical and subtropical areas including Aceh, a province that is located at the Northern end of Sumatra, Indonesia. In Aceh, A. catechu L. is traditionally masticated either alone or as a quid along with a large variety of ingredients, such as betel leaf (family Piperaceae), Uncaria gambir, and slaked lime for the traditional ceremonial, cultural role. Not only in Indonesia, areca nut is also usually used in betel chewing common among the Indians and Malays as a breath freshener, digestive aid, worm expellant, aphrodisiac, and to maintain stamina [1]. It is claimed to possess effects such as euphoria, cooling, cold protection, a sense of well-being, palpitation, heightened alertness, and resistance to anger [1,2]. The seeds contain sugar (50-60\%), lipid (12.84-15\%), polyphenol (15\%), alkaloid (0.2-0.5\%), and dan carbohydrate (19.13\%) [3]. The activities of $A$. catechu L. are anthelmintic, antifungal, antibacterial, anti-inflammatory, antioxidant, insecticida, and laacidal [3-5]. The use of A. catechu L. extract as one of a potential herbal medicine was not only expected to be given orally but also as a topical medicine. Although a lot of literature showed many benefits of A. catechu L. extract in the community, however, no literature has shown the safety use of $A$. catechu L. extract on the skin.

Before the purpose of accessing A. catechu L. extract further as a medicinal ingredient and a potential external application for topical uses, it is necessary to assess the adverse effects that it could cause in mammals. Acute dermal toxicity is the adverse effects occurring within a short time of dermal application of a single dose of a test substance $[6,7]$. Assessment of a single dermal dose toxicity is an important part of any toxicology program for new consumer products to safeguard human beings against the possible adverse effects $[8,9]$.

\section{METHODS}

Plant material and extraction

$1 \mathrm{~kg}$ of A. catechu L. fresh nut was collected from A. catechu L. plantation in Aceh Besar Province, Indonesia, in September 2013. The nuts were identified and verified by Indonesian Institute of Sciences, Research Center for Biology, Cibinong, Bogor. The seeds of A. catechu L. were gathered and cleaned from the dirt and pulp (wet sorting process). Seeds were washed under running water and then cleaned and drained. Afterward, these seeds were initially dried in open air, protected from direct sunlight, and then continued to the drying process in the oven at $50^{\circ} \mathrm{C}$. The dried simplicia were crushed into powder using a blender and sifted with 20 meshes of sieves. The powder was kept in cleaned and sealed containers. The extract was prepared by diluting the powder in water in directly applicated dermally to the rats.

\section{Animals}

The experiments were performed using healthy young adult female Sprague-Dawley rats, nulliparous, non-pregnant and weighing 170-184 g, age 3-4 month. Female rats were chosen because of their sensitivity to treatment [10]. They were procured from Histology Laboratory of Faculty of Medicine, Indonesia University, Jakarta, Indonesia. All animals were put in stainless steel, open-mesh cages in a room maintained under environmentally controlled conditions of $25-27^{\circ} \mathrm{C}$, a $12 \mathrm{hrs}$ light-dark cycle, and $40-60 \%$ relative humidity. The rats were acclimated for at least 5 days in the laboratory. The animals were fed with standard laboratory animal food pellets with water ad libitum. After the acclimation period, the rats were categorized into two groups (each contain of 5 rats), received the same handling conditions as during the acclimation process, and put into individual cages. During the $17^{\text {th }}$ to $20^{\text {th }}$ hrs of fasting period, the rats were fed only with plain water. All procedures were conducted in accordance with the 
European Community guidelines (EEC directive of 1986; 86/609/EEC) and were approved by the Animal Ethics Committee of the Faculty of Medicine, Indonesia University.

\section{Skin preparation for acute dermal toxicity study}

The hairs on the dorsal skin surface (About $6 \times 8 \mathrm{~cm}^{2}$ ) of animals were carefully shaved 24 hrs using razor blade before application. Based on OECD guidelines 402 , not $<10 \%$ of the body surface area should be clear for the application of the test substance.

\section{Experimental design for acute dermal toxicity}

An intense dermal toxicity test was made in accordance with the guidelines no 402 given by the OECD for the chemical testing [6]. Before the test, the rats were selected randomly and assigned to the treatment and control groups. $24 \mathrm{hrs}$ before the test, fur was removed from the dorsal area of the trunk of the test animals by clipping. About $10 \%$ of the body surface area was cleared for the application of the test substance. The dorsum area was applied with the A. catechu L. aqueous extract, covered, and taped with a porous gauze dressing and nonirritating tape as shown in Fig. 1a. The positive control group received the dosage of $15,000 \mathrm{mg} / \mathrm{kg}$ of white soft paraffin $10 \%$ as a vehicle. This dose was applied locally only once on the $1^{\text {st }}$ day of the study. At the end of the exposure period, the residual test substance was removed, where practicable using water. Based on OECD guideline 402, a limited test at one dose level at least $2000 \mathrm{mg} / \mathrm{kg}$ body weight, whereas the positive control group received the same dosage [6]. These doses were applied locally only once on the $1^{\text {st }}$ day of the study.

\section{Clinical observation}

Rats from both experiments were clinically checked once on the $1^{\text {st }}$ day of the study. Rats were monitored for the duration of $24 \mathrm{hrs}$, with special attention given to the first $6 \mathrm{hrs}$ and once daily further for 14 days. The rats were weighed and visual observations for mortality. Changes in the weight of individual animals were calculated and compared with that control animals as stated in OECD guidelines 402 [6]. The time of death must be recorded as precisely as possible. Particular attention should be directed to observations of behavior patterns such as salivation, tremors, convulsions, diarrhea, lethargy, sleep, and coma. The changes in physical appearance, injury, pain, and signs of illness were conducted once daily during the period, as well as any changes in skin, eyes, and mucous membranes and also respiratory rate, circulatory, autonomic, central nervous system, and behavior patterns.

\section{Pathological observation}

On the last day of observation, all rats were decapitated and examined macroscopically. Anomalies in the internal organs were documented and examined microscopically. After these thorough examinations were done, the remaining rats and tissue were sacrificed and discarded.

\section{Statistical analysis}

Statistical analysis of LD50 value was performed using ThompsonWeil with 95\% confidence interval. Comparisons were made between before and after treatment by the use of $t$-paired test. A $p=0.05$ or less $(\mathrm{p}<0.05)$ was considered as significant. All data were expressed as mean \pm standard error of the mean

\section{RESULTS}

\section{General sign and behavior of the rats}

$2 \mathrm{hrs}$ after the application of $15,000 \mathrm{mg} / \mathrm{kg}$ body weight of the A. catechu $\mathrm{L}$. aqueous extract dermally, the rats were becoming less active for $2 \mathrm{hrs}$. On the $2^{\text {nd }}$ day, after removing the gauzes from the skin, the rats were becoming less active for 30 minutes. No poisonous signs were seen in any rats, which made due up to 14 days in the wake of applying of the concentrates once on the $1^{\text {st }}$ day at single measurements level of $15,000 \mathrm{mg} / \mathrm{kg}$ body weight. There were no changes in skin and fur, eyes, mucous membrane, behavior patterns, salivation, lethargy, sleep, diarrhea, coma, and tremors. The observable examples of rats were watched initially $6 \mathrm{hrs}$ and pursued by $24 \mathrm{hrs}$ in the wake of applying the concentrates. The rats in both groups did not show any critical changes in conduct, skin impacts, breathing, disability in nourishment admission and water utilization, postural variations from the normal state and losing hair.

Weight loss was observed on the $2^{\text {nd }}$ day, but the weight increased again in the following days. Afterward, weight gain was observed until the end of observation. No mortality was observed during 14 days after treatment with aqueous extract of $A$. catech $u$ L. A significant difference on the weight gain, pre- and post-administration of $A$. catechu $\mathrm{L}$. aqueous extract is shown in Table 1 . There were no irritation signs on the skin. We found no erythema, eschar, edema, or any other reactions were observed in either intact or abraded site of all rats as shown in Fig 1b. There were no abnormal findings from a gross pathological examination of all internal organs at necropsy in the group. Based on these results, the oral LD50 of A. catechu L. aqueous extract is suggested to be $>5000 \mathrm{mg} / \mathrm{kg}$ body weight for female rats and this extract should, therefore, be labeling as unclassified nontoxic in the hazard category according to Globally Harmonized System (OECD-hazard). At the end of the observation period, all rats were decapitated. From the autopsies, no macroscopic anomalies were seen in the internal organs.

\section{DISCUSSION}

A desirable characteristic of any drug is that it has therapeutic effects at low dosages and has the least amount of undesirable secondary and toxic effects on individuals [11]. The results of this study, following the guidelines of the OECD, showed that the $A$. catech $u$ L. extract which has been evaluated in this study was included in unclassified nontoxic in rats at a dosage of $15,000 \mathrm{mg} / \mathrm{kg}$ body weight. A. catech $u$ L. constituents are known through several experiments to have beneficial effects on skin, suggesting the possible use in cosmetics industries [12,13]. Hence, this study might explain the importance of investigating the safety use of A. catechu L. extract on the skin.

Organ weight likewise is a vital record of physiological and obsessive status in creatures. The relative organ weight is major to finding, whether the organ was presented to the damage or not [14]. A decreased body weights on the $2^{\text {nd }}$ day were thought to be caused by the stress given by taping for the treatment since it happened in both control and treatment. The body weight gain of experimental animals and control group is an indicator of the degree of wellness and health of the rats. This finding indicates that high oral dosage of the A. catechu $L$. extract has an effect on the general well-being of the treated rats.

Skin is a barrier that keeps body water in and microorganisms and noxious chemicals out. Topical drugs, the mainstay of treatment in dermatology, are applied in the hope and expectation that any percutaneous absorption will be minimal and that systemic side effects will not occur [15]. The superficial layers of the epidermis, the stratum corneum, provide almost all the skin's barrier properties. Most drug absorption is transcellular; it is unlikely that noticeable absorption occurs between cells or through sweat pores and hair follicles. It is a passive diffusion process, the magnitude of which will depend on the integrity and efficacy of the epidermal barrier but which will be influenced by the drug itself [15]. Drugs with low molecular weight (below 800 daltons) with a high water and lipid solubility show the greatest penetration. The vehicle that contains the applied drug is important. So too is the degree of hydration of the stratum corneum, occluding the epidermis increases its water content, enhancing drug absorption. The rate of drug transport depends not only on its aqueous solubility but is also directly proportional to its oil/water partition coefficient, its concentration in the formulation vehicle, and the surface area of the skin to which it is exposed; it is inversely proportional to the thickness of the stratum corneum [15].

Polyphenols are the large numbers of a natural phenolic compound found abundantly in plants, possessing antioxidant activity. They are diverse in their chemical structure, nature and biological activity, capable of providing protection against oxidative stress and thus may play a significant role in the prevention or improvement of several 
Table 1: Effect of aqueous extract of $A$. catechu $\mathrm{L}$. on sprague dawley rats body weight at $15,000 \mathrm{mg} / \mathrm{kg}$ body weight

\begin{tabular}{llll}
\hline Groups & Treatment & Body weight & p value \\
\cline { 3 - 3 } & & Before treatment M1 \pm SD1 & After treatment M2 \pm SD2 \\
\hline Control & Soft paraffin 10\% & $172.80 \pm 6.87$ & $182.40 \pm 7.40$ \\
Dermal & $15,000 \mathrm{mg} / \mathrm{kg} \mathrm{BW}$ & $174.00 \pm 5.65$ & $182.80 \pm 6.87$ \\
\hline
\end{tabular}

*Significant, M1, SD1, M2, and SD2 are mean weight and standard deviation respectively for 1 (before treatment) and for 2 (after treatment), p<0.05: Statistically significance. SD: Standard deviation, BW: Body weight, A. catechu L.: Areca catechu Linn.

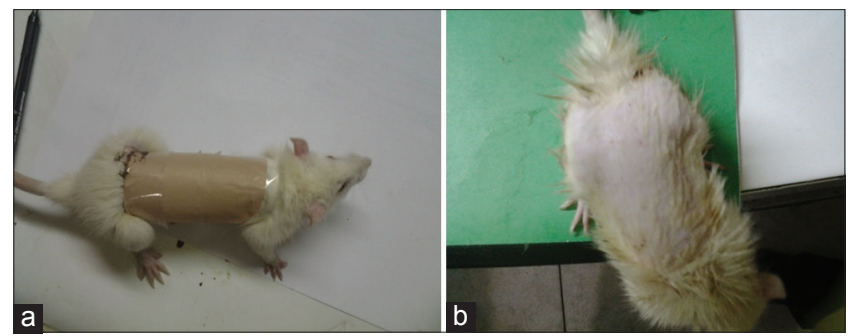

Fig. 1: (a) Clipped area of the skin was covered with non-irritating tape. (b) Clipped area of the skin after the removal Areca catechu Linn. aqueous extract application (dosage $15,000 \mathrm{mg} / \mathrm{kg} \mathrm{bw}$ )

clinical conditions like Cancer, osteoporosis, neurodegenerative, cardiovascular diseases, diabetes mellitus. The A. catechu L. nut contains a number of chemical components such as phenolic compounds (flavonoid, safrole, tannins, gallic acid, and catechin). It also contains alkaloids (arecoline, arecaidine, guvacine, and guvacoline) [4]. Flavonoids are polyphenolic compounds that are ubiquitous in nature and are categorized according to chemical structures into flavonols, flavones, flavonoids, isoflavonoids, catechins, anthocyanidins, and chalcones $[1,16]$. The absorption of flavonoid into the human skin has not been tested. However, from a single topical dose of catechin in green tea, maximal concentrations of $1.366 \mu \mathrm{g} / \mathrm{mL}$ and $411 \mu \mathrm{g} / \mathrm{mL}$ were measured in mouse epidermis and dermis, respectively [17]. The mechanisms of flavonoids are through the scavenging or chelating process. Hamsar et al. showed that the A. catechu L. extract has the proton-donating ability and could serve as free radical inhibitors or scavengers, acting possibly as primary antioxidant [1]. This promise has led to an explosion in nutrient containing products which are marketed for skin health improvement. The A. catechu L. extract, which is nontoxic, both cosmetic and consumable, can be considered as antioxidant nutrients for topical use.

\section{CONCLUSION}

Our results had demonstrated that the $A$. catech $u$ L. aqueous extract possesses nontoxicity effects as indicated in Sprague-Dawley rats. No deaths or indications of poison presence were seen in rats that received the extract up to a dermal acute limit dose of $15,000 \mathrm{mg} / \mathrm{kg}$ body weight. However, since the $A$. catech $\mathrm{L}$. is the main constituent responsible for oral squamous cell carcinoma, therefore, A. catechu $\mathrm{L}$. deserves more attention by the scientific community to explore its full range of benefits for clinical applications.

\section{REFERENCES}

1. Hamsar MN, Ismail S, Mordi MN, Ramanathan S, Mansor SM. Antioxidant activity and the effect of different parts of Areca catechu extracts on Glutathione-S-Transferase activity in vitro. Free Rad Antiox 2011;1:28-33.

2. Wang SM, Ling YC, Tsai LC, Giang YS. Headspace sampling and gas chromatographic-mass spectrometric determination of amphetamine and methamphetamine in betel. J Chromatogr 1995;75:325-31.

3. Wetwitayaklung P, Paechamud T, Limmatvapirat C, Keokitichai S. The study of antioxidant capacity in various parts of Areca catechu L. Naresuan Univ J 2006;14:1-14.

4. Xing Z, Jiao W, Zhuang H, Li MW, Fu DH. Antioxidant and cytotoxic phenolic compounds of areca nut (Areca catechu L.). Chem Res Chin Univ 2010;26:161-4.

5. Hannan A, Karan S, Chatterjee TP. A comparative study of in vitro antioxidant capacity of different extract of areca seed collected from Areca catechu plant grown in Assam. Int J Pharm Pharm 2012;4:420-7.

6. OECD. Acute Demal Toxicity 402. Paris: Organisation for Economic Co-operation and Development; 1987. p. 1-7.

7. Sari LM, Suyatna FD, Utami S, Chairul C, Subita GP, Whulandhary YS, et al. Acute oral toxicity study of Areca catechu Linn. Aqueous extract in sprague dawley rats. AJPCR 2014;7:20-2.

8. Han SM, Lee GG, Park KK. Acute dermal toxicity study of bee venom (Apis mellifera L.) in Rats. Toxicol Res 2012;28:99-102.

9. Vinardell MP, Mitjans M. Alternative methods for eye and skin irritation tests: An overview. J Pharm Sci 2008;97(1):46-59.

10. Lalitha P, Sripathi SK, and Jayanthi P. Acute toxicity study of extracts of Eichhornia Crassipes (Mart.) Solms, Asian J Pharm Clin Res, 5 (2012) 59-61.

11. Prado-Ochoa MG, Gutiérrez-Amezquita RA, Abrego-Reyes VH, Velázquez-Sánchez AM, Muñoz-Guzmán MA, Ramírez-Noguera P, et al. Assessment of acute oral and dermal toxicity of 2 ethyl-carbamates with activity against Rhipicephalus microplus in rats. Biomed Res Int 2014;2014:1-10.

12. Ashawat MS, Shailendra S, Swarnlata S. In vitro antioxidant activity of ethanolic extracts of Centella asiatica, Punica granatum, Glycyrrhiza glabra and Areca catechu. Res J Med Plant 2007;1:13-6.

13. Surendiran NS, Yuvaraj TV. Antibacterial, antioxidant, in vitro and in vivo immuno-modulatory studies of Areca catechu in mice. J Pharm Res 2010;3:2678-81.

14. Zahi AK, Hamzah H, Hutheyfa S, Shaari MR, Sithambaram S, Othman HH. Acute and sub-acute dermal toxicity studies of Morinda citrifolia L. Fruit extract in sprague dawley rats. AJPCR 2015;8(2):400-8.

15. Rutter N. Drug absorption through the skin: A mixed blessing. Arch Dis Child 1987;62(3):220-1.

16. Nijveldt RJ, van Nood E, van Hoorn DE, Boelens PG, van Norren K, van Leeuwen PA. Flavonoids: A review of probable mechanisms of action and potential applications. Am J Clin Nutr 2001;74(4):418-25.

17. Evans JA, Johnson EJ. The role of phytonutrients in skin health. Nutrients 2010;2(8):903-28. 